\title{
Production and Characterization of a Polyclonal Antibody of Anti-rLipL21-IgG against Leptospira for Early Detection of Acute Leptospirosis
}

\author{
Arivudainambi Seenichamy, Abdul Rani Bahaman, \\ Abdul Rahim Mutalib, and Siti Khairani-Bejo \\ Department of Veterinary Pathology and Microbiology, Faculty of Veterinary Medicine, Universiti Putra Malaysia, \\ 43400 Serdang, Selangor, Malaysia \\ Correspondence should be addressed to Abdul Rani Bahaman; rani@upm.edu.my
}

Received 7 January 2014; Revised 11 March 2014; Accepted 1 April 2014; Published 22 April 2014

Academic Editor: Marcelo A. Soares

Copyright (C) 2014 Arivudainambi Seenichamy et al. This is an open access article distributed under the Creative Commons Attribution License, which permits unrestricted use, distribution, and reproduction in any medium, provided the original work is properly cited.

\begin{abstract}
Leptospirosis is one of the zoonotic diseases in animals and humans throughout the world. LipL21 is one of the important surface-exposed lipoproteins in leptospires and the most effective cross protective immunogenic antigen. It is widely considered as a diagnostic marker for leptospirosis. In this study, we evaluated the serodiagnostic potential of LipL21 protein of Leptospira interrogans serovar Pomona. We have successfully amplified, cloned, and expressed LipL21 in E. coli and evaluated its specificity by immunoblotting. Purified recombinant LipL21 (rLipL21) was inoculated into rabbits for the production of polyclonal antibody. Characterization of the purified IgG antibody against rLipL21 was performed by cross reactivity assay. Only sera from leptospirosis patients and rabbit hyperimmune sera recognized rLipL21 while the nonleptospirosis control sera showed no reaction in immunoblotting. We confirmed that anti-rLipL21-IgG antibody cross reacted with and detected only pathogenic leptospiral species and it did not react with nonpathogenic leptospires and other bacterial species. Results observed showed that anti-rLipL21-IgG antibody has high specificity and sensitivity to leptospires. The findings indicated that the antibody could be used in a diagnostic assay for detection of leptospires or their proteins in the early phase of infection.
\end{abstract}

\section{Introduction}

Leptospirosis is a major public health concern and has now been identified as one of the emerging infectious diseases worldwide $[1,2]$. It is highly prevalent in the Asia Pacific region [3]. In Malaysia, leptospiral infections seen in domestic animals were mainly due to serovars of the Sejroe and Pomona serogroups. The infections in humans were also due to Leptospira interrogans serovar Pomona [4]. It is considered that the majority of leptospirosis cases in humans were due to association with animals and disease-infected environment [5]. Leptospirosis displays a wide array of clinical presentations and it is difficult to distinguish from dengue, malaria, and influenza. It mimics many other diseases characterized by fever, headache, and myalgia [6]. After clearance of leptospires from blood and body fluids, they are known to persist for prolonged periods in immune privileged sites like renal tubules, brain, and eyes of carrier animals [7]. Leptospires include 268 serovars [8] and can be organised into 31 serogroups on the basis of their antigenic relatedness [5]. The antigenic structure of leptospires is complex, with structural heterogeneity in the carbohydrate component of the lipopolysaccharides (LPS) [7]. The outer membrane of leptospires is composed of immunogenic LPS and different types of outer membrane proteins (OMPs). Lipopolysaccharides play a key role in immunity to infection and are responsible for serovar variations [9]. Based on serological classification, the genus Leptospira was earlier classified into two species, the pathogenic L. interrogans and nonpathogenic L. biflexa.

The leptospiral membrane possesses at least three types of OMPs: lipoproteins, peripheral OMPs, and transmembrane 
TABLE 1: Leptospiral strains used in the LipL21 studies.

\begin{tabular}{lccc}
\hline Leptospira & Species & Serovar & Strain \\
\hline & L. interrogans & Pomona & Pomona \\
L. interrogans & Canicola & Hond Utrecht IV \\
L. interrogans & Hardjo & Sponselee \\
L. interrogans & Autumnalis & Djasiman A \\
L. interrogans & Djasiman & Moskva V \\
Lathogenic & L. interrogans & Hebdomadis \\
& L. interrogans & Grippotyphosa & Valdrat Batavia 46 \\
& L. interrogans & Hebdomadis & Ballico \\
& L. interrogans & Javanica & RGA \\
L. icterohaemorrhagiae & Australis & Bejo-Iso 9 \\
\hline Nonpathogenic & L. kmetyi & Icterohaemorrhagiae & Patoc 1 \\
\hline
\end{tabular}

proteins [10, 11]. Among them LipL21 was described as one of the most important outer membrane lipoproteins produced during leptospiral infection [12]. Detection and identification of conserved leptospiral lipoproteins among pathogenic leptospires were made through cross-protection assays against various serovars of leptospires. The exclusive presence of these proteins in the pathogenic leptospires indicated that they could be promising candidates for developing diagnostics [13]. Hence these lipoproteins have currently become a major focus of leptospirosis research [14].

In the present study, we expressed the recombinant protein LipL21 and evaluated its immunogenic potential with leptospirosis human sera and rabbit hyperimmune sera. We used purified, recombinant LipL21 to create polyclonal immunoglobulin $\mathrm{G}$ (IgG) against rLipL21. The results of the present study provide a possible new candidate for developing diagnostic kit for detecting leptospires and/or their leptospiral antigen during the early stages of infection.

\section{Materials and Methods}

2.1. Bacterial Strains and Growth Conditions. In this study, leptospiral reference strains were obtained from WHO Collaborating Centre Brisbane, Queensland, Australia, as shown in Table 1. Other bacterial strains used in the study include E. coli, Pseudomonas aeruginosa, Staphylococcus aureus, Pasteurella multocida, Bacillus subtilis, Salmonella typhi, Klebsiella pneumoniae, and Proteus spp. These were kindly provided by the bacteriology Lab, Faculty of Veterinary Medicine in University Putra Malaysia. Escherichia coli DH-5 $\alpha$ (lab collection) and BL21 (DE3) (Novagen, Madison, WI) were used for cloning and expression to purify the recombinant protein. Leptospires were grown to mid-logarithmic phase for 7 days at $30^{\circ} \mathrm{C}$ in liquid Ellinghausen-McCullough-JohnsonHarris (EMJH) medium. The E. coli strains were routinely grown in Luria-Bertani (LB) medium at $37^{\circ} \mathrm{C}$, with appropriate selection pressure (ampicillin $(50 \mu \mathrm{g} / \mathrm{mL})$, kanamycin $(50 \mu \mathrm{g} / \mathrm{mL})$, and chloramphenicol $(34 \mu \mathrm{g} / \mathrm{mL}))$.
2.2. Amplification and Cloning of LipL21. Leptospira spp. were grown in EMJH medium to mid-log phase for DNA extraction. Genomic DNA extracted from $1 \times 10^{8}$ cells using the Promega Wizard genomic DNA purification kit (Promega, Madison, WI, USA). The new primers designed were based on comparison of 56601 sequences retrieved from GenBank (Gene ID: 1149354) of L. interrogans serovar Lai strain. The primers used for the amplification of lipL21 gene are FL21$5^{\prime}$ GAG AAG CATATG ATC AAT AGA CTT ATA GC $3^{\prime}$ with restriction site NdeI and RL21-5' -CCC GAATTC TTA TTG TTT GGA AAC CTC TTG-3' with restriction site EcoRI. The resulting amplicon was digested with restriction enzymes NdeI and EcoRI and inserted into pET-28(b) vector (Novagen). The recombinant plasmid construct was confirmed for accurate insertion by both restriction enzyme digestion and sequencing.

2.3. Expression of Recombinant LipL21 Fusion Protein. The pET28-LipL21 (pEL21) plasmid was transformed into $E$. coli BL21 (DE3) (Novagen) [15]. A single colony of E. coli BL21 (DE3) harbouring the pET28-LipL21 (pEL21) plasmid was inoculated into $10 \mathrm{~mL} \mathrm{LB}$ media containing $50 \mu \mathrm{g} / \mathrm{mL}$ kanamycin and incubated overnight at $37^{\circ} \mathrm{C}$ with shaking at $200 \mathrm{rpm}$. An aliquot of $100 \mu \mathrm{L}$ of the overnight cell culture was added to another tube of $10 \mathrm{~mL}$ LB medium (containing $50 \mu \mathrm{g} / \mathrm{mL}$ kanamycin and Overnight Express Autoinduction System 1) (Novagen) and incubated at $20^{\circ} \mathrm{C}$ with shaking $(200 \mathrm{rpm})$. The overnight induced culture was harvested aseptically by centrifugation at $12,000 \mathrm{~g}$ for $3 \mathrm{~min}$. E. coli BL21 (DE3) cells harbouring the pEL21 vector were used as the uninduced or negative control. Bacterial pellets recovered after inductions were dissolved in appropriate volume of Laemmli buffer and proteins were resolved on a $12 \%$ SDSPAGE. The expression of the recombinant LipL21 (rLipL21) was detected by Western blot using the His tag AP Western blot kit (Novagen). Protein concentrations were determined by using a bicinchoninic acid (BCA) protein assay kit (BioRad). 
2.4. Purification of rLipL21 Fusion Protein. For auto induction, 1 litre culture was incubated at $20^{\circ} \mathrm{C}$ for $18 \mathrm{~h}$ with orbital shaking (190 rpm), using the Overnight Express Auto Induction System 1 according to the specifications provided by the manufacturer (Novagen). After the induction period, the cells were collected by centrifugation for $10 \mathrm{~min}$ at $12,000 \mathrm{~g}$ at $4^{\circ} \mathrm{C}$, resuspended in one-tenth of the culture volume of binding buffer $\left(50 \mathrm{mM} \mathrm{NaH}_{2} \mathrm{PO}_{4}, 300 \mathrm{mM} \mathrm{NaCl}, 10 \mathrm{mM}\right.$ imidazole, $\mathrm{pH}$ 8.0) and subjected to sonication (Branson ultrasonifier, USA) till complete cell lysis. The lysates of induced culture are cleared by centrifugation at $12,000 \mathrm{~g}$ for $30 \mathrm{~min}$ at $4^{\circ} \mathrm{C}$ and were applied on a His-Trap (Novagen) of $\mathrm{Ni}^{2+}$-nitrilo-triacetic acid (Ni-NTA) affinity column $(2 \mathrm{~mL})$. Ni-NTA column was preequilibrated with binding buffer (50 $\mathrm{mM} \mathrm{NaH} \mathrm{PO}_{4}, 300 \mathrm{mM} \mathrm{NaCl}, 10 \mathrm{mM}$ imidazole, $\mathrm{pH}$ $8.0)$ and finally it was washed using wash buffer $(50 \mathrm{mM}$ $\mathrm{NaH}_{2} \mathrm{PO}_{4}, 50 \mathrm{mM} \mathrm{NaCl}, 10 \mathrm{mM}$ imidazole, $\mathrm{pH}$ 8.0) to remove the unbound proteins. Bound proteins were eluted with elution buffer $\left(50 \mathrm{mM} \mathrm{NaH}_{2} \mathrm{PO}_{4}, 300 \mathrm{mM} \mathrm{NaCl}, 250 \mathrm{mM}\right.$ imidazole, $\mathrm{pH}$ 6.0). The eluted recombinant LipL21 protein was dialysed and concentrated by Centriprep-30 (10 kDa cut off) (Millipore-Amicon, Beverly, MA). The protein concentration was determined by BCA method. The purity of LipL21 protein was analysed by $12 \%$ SDS-PAGE and visualized by staining with Coomasie brilliant blue [16].

2.5. Polyclonal Antibody Production. Polyclonal antibody production was carried out according to the method of Shang et al. [17]. Purified rLipL21 protein was loaded onto SDS-12\% polyacrylamide gel and separated during electrophoresis. A rLipL21 containing band was excised from the gel and desiccated. The desiccated gel containing recombinant protein was ground to a powder, dissolved in $1 \mathrm{~mL}$ of water, and mixed with $1 \mathrm{~mL}$ of complete Freund's adjuvant (Merck, Whitehouse Station, NJ). New Zealand White rabbits (free of leptospiral antibodies) were immunized with the mixture of rLipL21 and complete adjuvant (subcutaneously and intramuscularly) on Day 1. Additional immunization with the same dosage of rLipL21 with incomplete Freund's adjuvant (Merck) was done on Day 14, Day 28. On Day 42 the rabbits were bled by heart puncture and the serum was tested to detect antibodies against LipL21. The LipL21-antiserum was stored in small aliquots at $-20^{\circ} \mathrm{C}$ until use. Animals were housed in accordance with the ethical principles and experimental procedures with animals were approved by the Animal Care and Use Committee of the Faculty of Veterinary Medicine, University Putra Malaysia (AUP No: 09R57/Mac 09-Feb10).

2.6. Purification of IgG from Rabbit Serum. To obtain purified polyclonal immunoglobulin, whole serum supernatant was used in Montage Antibody Purification Kits with PROSEP-A (LSK2 ABA 20, Millipore). Immunized rabbit antiserum containing $\operatorname{IgG}$ was purified according to the manufacturer's instructions.

2.7. OMPs Separation by Triton X-114. To validate whether proteins are present in the leptospiral OMPs, Triton X-114 cellular fractionation was carried out in leptospiral lysates according to previously described method [14, 18]. Briefly, leptospires were grown to mid-log phase and the cells washed with phosphate buffer saline (PBS) containing $5 \mathrm{mM} \mathrm{MgCl}_{2}$ buffer and then resuspended in lysis buffer (1\% Triton X114 containing $150 \mathrm{mM} \mathrm{NaCl}, 20 \mathrm{mM}$ Tris ( $\mathrm{pH} 8), 2 \mathrm{mM}$ EDTA, and $1 \mathrm{mM}$ phenylmethylsulfonyl fluoride) at $4^{\circ} \mathrm{C}$. Insoluble materials of leptospiral OMP were removed by centrifuging at $17,000 \mathrm{~g}$ for $10 \mathrm{~min} .20 \mathrm{mM} \mathrm{CaCl}_{2}$ was added to half of the supernatant; the supernatant was warmed to $37^{\circ} \mathrm{C}$ and subjected to centrifugation for $10 \mathrm{~min}$ at $2,000 \mathrm{~g}$ for phase separation. Acetone precipitation was performed to separate detergent (outer membrane proteins) and aqueous (periplasmic) phases [19].

2.8. Rabbit Antiserum. Rabbit antiserum against Leptospira spp. serovar Australis (strain Ballico), Bataviae (strain Swart), Cynopteri (strain 3522C), Canicola (strain Hond Utrecht IV), Grippotyphosa (strain Moskva V), Hebdomadis (strain Hebdomadis), Javanica (Valrat Batavia 46), Pomona (strain Pomona), Icterohaemorrhagiae (strain RGA), Tarasovi (strain Perepelistin), Cellodoni (strain Cellodoni), Pyrogenes (strain Salinum), Hardjobovis (strain Sponselee), and Hardjo (strain Hardjoprajito) were obtained from WHO Collaborating Centre, Brisbane, Queensland, Australia.

2.9. Human Patient Samples. Five leptospirosis confirmed patient serum samples (positive control) and nonleptospirosis serum sample, which is similar like leptospirosis clinical symptoms (negative control), was obtained anonymously from the Institute for Medical Research (IMR) (http://www.imr.gov.my), Kuala Lumpur, Malaysia, for research purpose and it was incorporated into our research project. The negative control serum sample mentioned above was from a nonleptospirosis patent with clinically similar symptoms of leptospirosis. The serum samples were then evaluated by immunoblotting against rLipL21 antigens.

2.10. SDS-PAGE and Immunoblotting. Leptospires membrane fractions or purified proteins of rLipL21 were resolved on SDS-PAGE. The separated proteins were electrotransferred onto a nitrocellulose (NC) membrane (Millipore). The membrane was blocked with TBS $(150 \mathrm{mM} \mathrm{NaCl}, 50 \mathrm{mM}$ Tris-HCl, pH 7.4) containing $0.05 \%$ Tween 20 (T-TBS) and $3 \%$ bovine serum albumin at $37^{\circ} \mathrm{C}$ for $2 \mathrm{hrs}$. After the T-TBS wash, the membrane was incubated with primary antibody overnight and then washed with T-TBS. The membrane was then incubated with alkaline phosphatase conjugated secondary antibody at $37^{\circ} \mathrm{C}$ for $2 \mathrm{hrs}$. The NC membrane was then developed by BCIP and NBT substrates. The LipL21 band was visualized by the dark blue colour. The enzyme reaction on the membrane was terminated by washing with distilled water [20].

In order to detect recombinant protein of rLipL21, the protein was resolved on SDS-PAGE gel. The protein was then transferred to NC membranes (Millipore) and immunoblotted using the $1: 20,000$ dilution of primary rabbit antiserum (against Leptospira spp.) and 1:100 dilution 


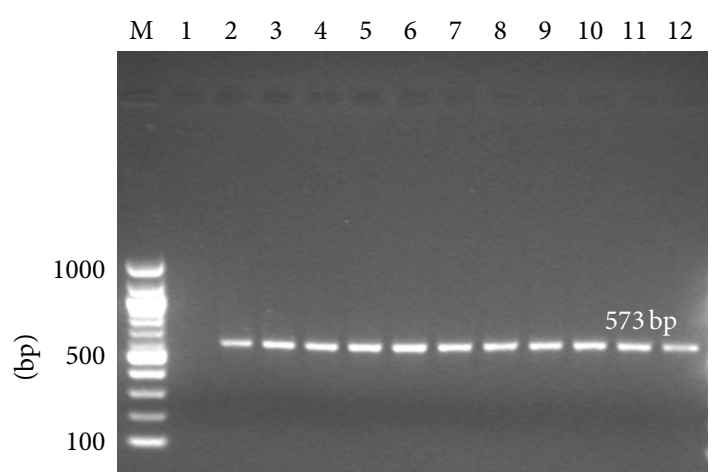

Figure 1: PCR amplified lipL21 gene from different serovars: Lane M: $1 \mathrm{~kb}$ marker; Lane 1: nonpathogenic species Leptospira biflexa (strain Patoc 1); Lane 2: Canicola (strain Hond Utrecht IV); Lane 3: Hardjobovis (Sponselee); Lane 4: Autumnalis (strain Akiyami A); Lane 5: Icterohaemorrhagiae (strain RGA); Lane 6: Australis (strain Ballico); Lane 7: Pomona (strain Pomona); Lane 8: Grippotyphosa (strain Moskva V); Lane 9: L. kmetyi serovar Malaysia strain Bejo-iso $9^{T}$; Lane 10: Balum (strain Mus 127); Lane 11: Grippotyphosa (strain Moskva V); Lane 12: Hebdomadis (strain Hebdomadis).

of human serum (Calbiochem, Germany) overnight, followed by T-TBS wash thrice. The blot was incubated with $1: 10,000$ diluted alkaline phosphatase conjugated secondary goat anti-rabbit IgG (Calbiochem, Germany) or 1:10,000 diluted alkaline phosphatase conjugated secondary goat antihuman immunoglobulin (Calbiochem, Germany) at $37^{\circ} \mathrm{C}$ for 2 hours. The NC membrane (blot) was developed using BCIP and NBT substrates (Novagen, USA).

In order to determine if IgG created against the purified recombinant forms of these proteins could effectively bind to their cognate proteins found in the leptospires, OMP fraction and other fractions were resolved using SDS-PAGE and transferred to NC membranes. These membranes were then probed using purified anti-rLipL21-IgG at a 1:30,000 dilution of primary rabbit serum (anti-rLipL21) and goat antirabbit IgG-alkaline phosphatase (Calbiochem, Germany) at a 1:10,000 dilution as a secondary antibody, with BCIP and NBT substrates (Novagen, USA).

\section{Results}

3.1. Amplification of lipL21. Polymerase chain reaction was performed using lipL21 gene specific primers for detection of Leptospira spp. The expected size of amplified lipL21 gene from pathogenic leptospires strains was $573 \mathrm{bp}$. No amplification was observed from nonpathogenic leptospires (Figure 1) and other bacterial strains (data not shown). PCR amplification showed that lipL21 gene is conserved among Leptospira spp. only, and designed primer specifically amplified the lipL21 gene from pathogenic Leptospira spp. The DNA sequence was identified, analyzed, and deposited in the GenBank database (Table 2). Blast analysis showed that this sequence is $95 \%$ and $96 \%$ similar at the nucleotide and predicted amino acid levels, respectively, to the sequence of
TABLE 2: LipL21 gene accession number in the GenBank.

\begin{tabular}{lc}
\hline Pathogenic strains & GenBank \\
\hline L. interrogans strain Pomona & EU244328 \\
L. interrogans strain Ballico & FJ853169 \\
L. interrogans strain Hond Utrecht IV & FJ853170 \\
L. interrogans strain Akiyami A & FJ853171 \\
L. interrogans strain Hebdomadis & FJ853172 \\
L. interrogans strain RGA & FJ853173 \\
L. interrogans strain Moskva V & FJ853174 \\
L. interrogans strain Djasiman & FJ853175 \\
\hline
\end{tabular}

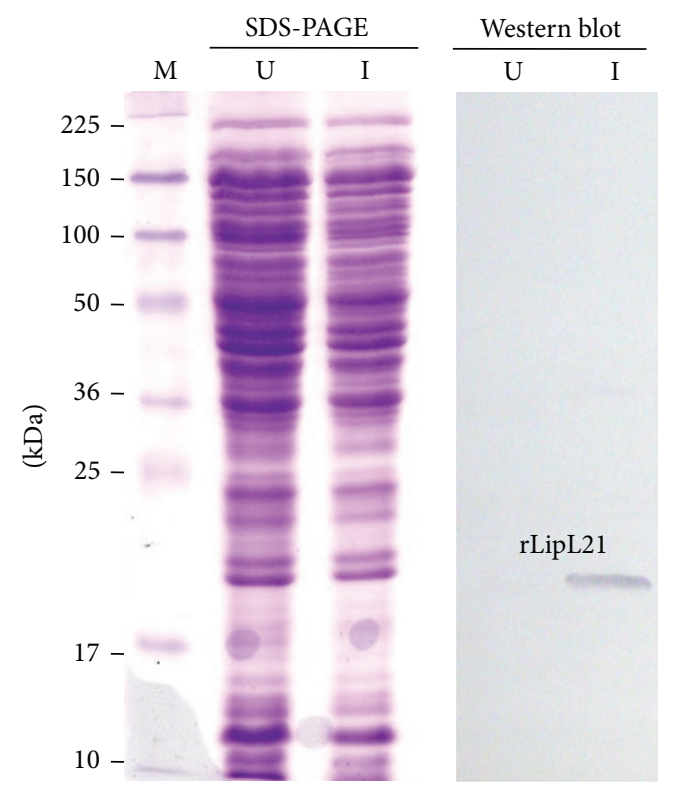

FIGURE 2: Expression analysis of rLipL21 on SDS-PAGE and Western blot. Lane U: uninduced lysates containing the pEL21 plasmid only; Lane I: auto induced lysates containing the pEL21 plasmid; Lane M: protein ladder.

annotated gene coding for lipL21 in the complete genome sequence of $L$. interrogans strain Lai.

3.2. Expression and Purification of His-Tagged LipL21 Protein. The rLip21 gene was cloned in an expression plasmid with an $\mathrm{N}$-terminal His tag and the construct was then transformed into E. coli BL21. His tag was used for the purification of recombinant LipL21 (rLipL21) by Ni-NTA affinity column. Aliquots of E. coli-induced cultures were analyzed on $12 \%$ SDS-PAGE and expression of rLipL21 protein was confirmed by Western blot with anti-His MAb (Figure 2). The blotted membrane indicated the presence of corresponding band in the expressed rLipL21 protein.

3.3. Immunoreactivity of rLipL21 Protein. The immunoreactivity of the rLipL21 protein against human sera confirmed leptospirosis infection was assessed by immunoblot analysis (Figure 3(b)) and five sera samples from clinically confirmed leptospirosis patients (Figure 3(b)). Figure 3(b) presents 


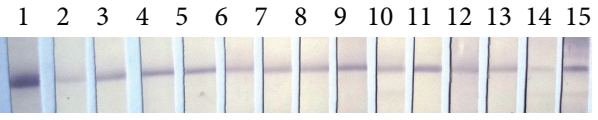

(a)

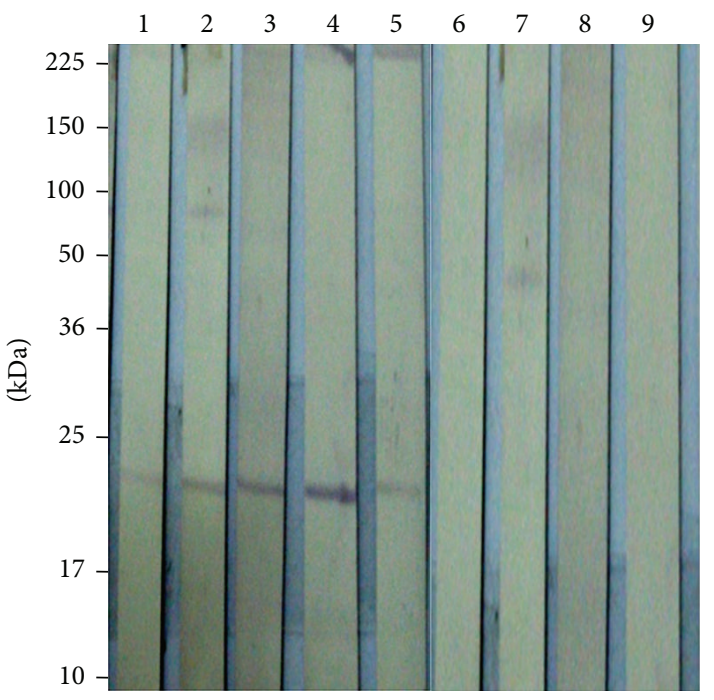

(b)

FIGURE 3: (a) Immunoblot reaction of rLipL21 protein recognized by different Leptospira spp. in serovar specific hyperimmune sera. Lane 1: His Tag monoclonal antibody; Lane 2: Australis (strain Ballico); Lane 3: Bataviae (strain Swart); Lane 4: Cynopteri (strain 3522C); Lane 5: Canicola (strain Hond Utrecht IV); Lane 6: Grippotyphosa (strain Moskva V); Lane 7: Hebdomadis (strain Hebdomadis); Lane 8: Javanica (Valrat Batavia 46); Lane 9: Pomona (strain Pomona); Lane 10: Icterohaemorrhagiae (strain RGA); Lane 11: Tarasovi (strain Perepelistin); Lane 12: Cellodoni (strain Cellodoni); Lane 13: Pyrogenes (strain Salinum); Lane 14: Hardjobovis (strain Sponselee); Lane 15: Hardjo (strain Hardjoprajito). (b) Immunoblots examining the reactivity of leptospirosis positive human sera with rLipL21. Lane 1-8: $0.5 \mu \mathrm{g}$ of purified recombinant rLipL21 was probed with sera from Malaysian leptospirosis patients; Lane 1-5: leptospirosis patient sera detected rLipL21; and Lane 6-9: nonleptospirosis sera (leptospiral like clinical symptoms) not detected rLipL21. Molecular weight standards are indicated in kilodaltons.

the typical reaction of serum samples obtained from patients with (lanes 1 to 5) and without (lanes 6 to 9) leptospiral infection to detect the rLipL21. The rLipL21 protein with rabbit hyperimmune sera was tested. Antibody against the whole Leptospira spp. was detected by immunoblotting in all hyperimmune sera tested, with strong signal intensity as observed (Figure 3(a)).

\subsection{Purification of Rabbit Anti-rLipL21 Immunoglobulins.} SDS-PAGE analysis of the purified IgG fraction of the antirLipL21 antiserum revealed two bands corresponding to the heavy and light chains of IgG (Figure 4). The protein content of this fraction was $45 \mathrm{mg}$ which was about one-third of primary protein content.

3.5. Specificity of Rabbit Anti-rLipL21-IgG Antibody. IgGenriched fractions (anti-rLipL21-IgG) were able to recognize

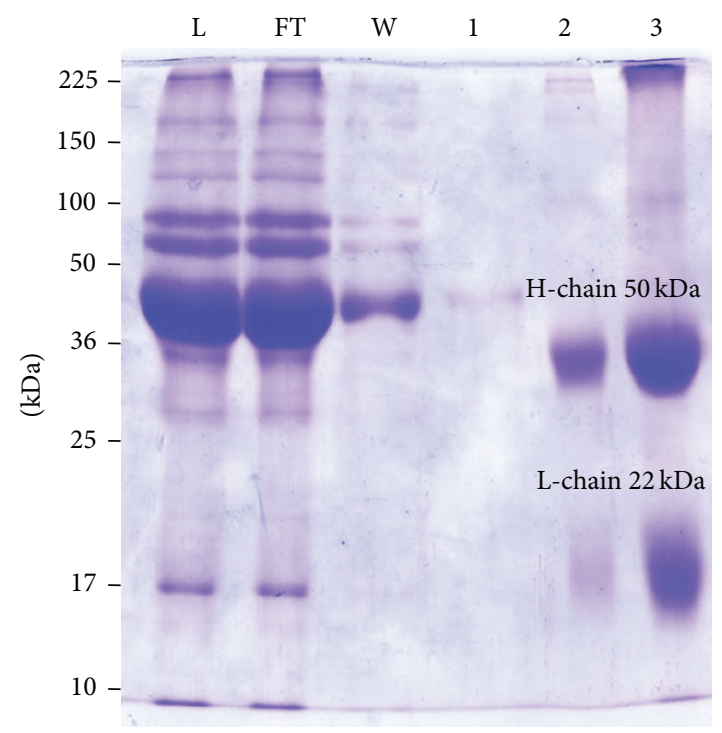

FIGURe 4: Purification of (anti-rLipL21) IgG antibody was purified from rabbit antiserum against rLipL21. Lane L: anti-rLipL21 serum; Lane FT: flow through of unbound proteins from column; Lane W: wash of nonspecific proteins from column; Lane 1: eluted fraction without protein; Lane 2: purified anti-rLipL21-IgG; Lane 3: concentrated anti-rLipL21-IgG. Molecular weight standards are indicated in kilodaltons.

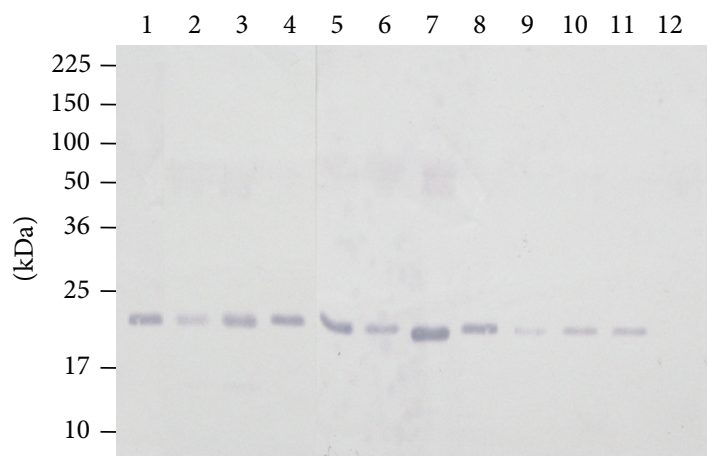

FIGURE 5: Immunoblot of panel of Leptospira spp. obtained by using rabbit anti-rLipL21-IgG antibody to detect single band in leptospiral LipL21 antigen in detergent phase. Lane 1: Canicola (strain Hond Utrecht IV); Lane 2: Hardjobovis (Sponselee); Lane 3: Autumnalis (strain Akiyami A); Lane 4: Icterohaemorrhagiae (strain RGA); Lane 5: Australis (strain Ballico); Lane 6: Pomona (strain Pomona); Lane 7: Grippotyphosa (strain Moskva V); Lane 8: L. kmetyi serovar Malaysia strain Bejo-iso $9^{T}$; Lane 9: Balum (strain Mus 127); Lane 10: Grippotyphosa (strain Moskva V); Lane 11: Hebdomadis (strain Hebdomadis); Lane 12: nonpathogenic species L. biflexa (strain Patoc 1). Molecular weight standards are indicated in kilodaltons.

leptospiral native LipL21 antigen by immunoblot, which demonstrated that the antibody was specific against LipL21 from pathogenic Leptospira spp. (Figure 5). Preimmune serum did not react with the rLipL21 proteins (data not shown). When these antibodies were tested against triton $\mathrm{X}$ 114 fraction of pathogenic serovars of Leptospira spp., they bound to proteins that corresponded to the molecular weight 
of the native protein. From this result, it can be assumed that the recombinant forms of the candidate antigens effectively mimic the properties of the native form.

\section{Discussion}

Leptospirosis is an important public health disease in endemic areas all over the world. In Malaysia, continuous presence of multiple leptospires serovars is observed in competent reservoirs like rat and other animals, and a large population of susceptible hosts [4]. Humans and animals infected with leptospires mount strong and rapid antibody responses directed against the outer surface protein, LipL21. The presence of LipL21-directed antibodies in patient serum is a reliable marker of leptospiral infection. Lipoproteins are an important antigen and play a key role in the pathogenesis of leptospirosis [14] and surface-exposed putative lipoproteins $[21,22]$. Several lipoproteins and surface-exposed putative lipoproteins have been identified in Leptospira spp., which are associated with the outer membrane particularly those exposed on the cell surface where bacterial pathogens interact with the host [23]. These lipoproteins are maintaining the bacterial cell structure, attachment to various substrates, and immunogenicity [5]. Among these lipoproteins, the LipL21 protein has been well characterized in L. interrogans serovar Lai [24]. LipL21 has been reported to be conserved in pathogenic leptospiral strains and this has led to its use in PCR-based identification of Leptospira spp. [7]. In this study, a PCR assay was performed using lipL21 gene specific primers for detection of Leptospira spp. The expected size (573 bp) of amplified lipL21 gene was seen in 11 pathogenic Leptospira strains but not observed in the nonpathogenic leptospiral strain (Figure 1). Similarly, the lipL21 gene specific primer did not amplify any other 10 bacterial strains (data not shown). The lipL21 gene specific primer would be useful for identification of pathogenic Leptospira spp. These PCR results corroborated well with previous reports that LipL21 is present only in pathogenic and absent in nonpathogenic strains [12, 25].

Genomic analysis revealed that the identified LipL21 proteins of $L$. interrogans strain Pomona were found to be 97$100 \%$ amino acids similar to other pathogenic Leptospira spp. An alignment of the LipL21 sequence from pathogenic Leptospira revealed $96 \%$ to $100 \%$ identity. They also did not have any significant similarity with the proteins of other organisms $[26,27]$. However, insights from recent genome projects have shown that nonpathogenic strain of L. biflexa LipL21 protein is an ortholog with $\sim 50 \%$ identity present in pathogenic leptospires [26]. Its exclusive presence in pathogenic leptospires indicated that this protein could be a good candidate in developing diagnostic kits [13].

Generally, important diagnostic and vaccine markers primarily induce antibodies against surface structures. Molecular analysis of leptospiral OMP antigens is important in understanding the antibody response of hosts, because the antigenic diversity may influence the specificity and sensitivity of the serological assay. The conserved nature and high level of expression of LipL21 among pathogenic Leptospira spp. [7] suggest that rLipL21 immunoblot may show similar performance regardless of the local isolates. E. coli based expression system is now routinely used for the synthesis of recombinant proteins for a variety of purposes ranging from structural studies to the development of vaccines $[11,12,19]$. Similarly, the purification of recombinant protein is important to develop a detection system for infectious diseases. The present work adopted similar approach for expression of LipL21 protein and purification of rLipL21 in E. coli cells (Figure 2).

Normally, E. coli based IPTG/NaCl induced expression system was used for the synthesis of recombinant lipoproteins from Leptospira spp. [28-30]. Drawback for the use of this system includes the requirement of expression conditions such as need to follow growth of bacterial culture and add IPTG/NaCl at the proper time. An advantage of the use of Overnight Auto Induction System 1 in the present study did not require any inducer including IPTG/NaCl.

In this study, an immunoblot using the rLipL21 protein as an antigen was evaluated for the diagnosis of leptospirosis in humans. In this study, we evaluated the clinical utility and the corresponding sensitivity and specificity of recombinant LipL21 based immunoblot for the serodiagnosis of leptospirosis. The specificity of the antibody test (immunoblot) with a rLipL21 protein detected by clinically confirmed leptospirosis patient sera (Figure 3(b)). In order to confirm the similarity of the antigenic structure of the recombinant forms of the LipL21 protein, as well as to verify the cell wall localization of LipL21, we carried out a simple immunoblot study in which we tested the ability of the recombinant proteins to react with serum from a rabbit (Figure 3(b)). The strong reactivity of the recombinant forms of LipL21 with the patient serum confirms the information from studies carried out previously $[12,31]$. Recombinant LipL21 was also reactive with this serum, meaning that LipL21 is immunogenic during leptospiral infection. This is probably because LipL21 protein is unique and highly conserved to pathogenic Leptospira spp. [12]. The specificity of LipL21 has been demonstrated to be strong immunogenic and could be an efficient tracer to LipL21 identification from Leptospira spp. Thus, use of the rLipL21 antigen in immunoblot has the potential to become a useful tool for serodiagnosis of leptospiral infection.

Lipoproteins may be used as novel targets for the development of infection markers and leptospirosis vaccines [5]. In pathogenic Leptospira spp., LipL21 has been demonstrated to be a strong immunogen, which had been considered for vaccine development $[12,27,29]$. Together, these findings suggest that rLipL21 antigen is specific and sensitive for the detection of antibodies against leptospiral infection. Both rabbit and human anti-leptospiral antibodies were found to be strongly reactive with rLipL21. Additional immunoblot results showed that the rLipL21 had the advantage of high specificity and sensitivity to leptospirosis. The present study follows the strategy of previous studies on rLipL32, rOmpL1, rLipL41, and rLigA as target antibodies used for clinical diagnosis of leptospirosis [32-35].

Although many of the cellular proteins were insoluble in the Triton X-114 or remained present in the aqueous phase, a limited number of proteins were present in the detergent phase, as previously described by Cullen et al. [12] and 
Haake et al. [28]. However, LipL21 protein was observed in the insoluble detergent phase and not observed in soluble phase [12]. Regardless of this, when we performed the converse study, the detergent fraction containing OMP antigen from Leptospira spp. and sera of immunized rabbit reacted against LipL21 antigen. Immunoblot of OMP fraction of Leptospira spp. using anti-rLipL21-IgG antibody revealed specificity of LipL21 antigen from pathogenic strains of leptospires (Figure 5). OMP fractions from the Leptospira spp. were LipL21 bound strongly detected by their anti-rLipL21-IgG antibodies. This result revealed that LipL21 is localized on the outer portion of the leptospires. This is the first demonstration of experimental characterization of the LipL21 from L. interrogans strain Pomona in Malaysia. Results from this study suggested that rLipL21 is a potential candidate for the serodiagnosis of leptospirosis. Further research is required to evaluate the effectiveness of this antigen with a larger number of samples obtained during outbreaks of leptospirosis. The polyclonal serum against rLipL21 protein was more specific for differentiating the pathogenic organism from nonpathogenic leptospires. Apart from these, our work revealed that the use of anti-rLipL21-IgG antibodies increases the specificity of the antigen detection. From these results, we conclude that the use of purified recombinant protein based antibody production is an appropriate and applicable method for detection of acute leptospirosis.

The polyclonal antibodies were highly sensitive but less specific in comparison to monoclonal antibodies. Monoclonal antibodies on the other hand were highly specific but less sensitive [36]. These data could have useful application to detecting LipL21 antigen from leptospires infection.

\section{Conflict of Interests}

The authors declare that there is no conflict of interests regarding the publication of this paper.

\section{Acknowledgments}

The authors acknowledge the technical assistance of $\mathrm{Mr}$. Mohd Azri Roslan from the Department of Veterinary Pathology and Microbiology, Faculty of Veterinary Medicine, University Putra Malaysia. This work was supported by the Science Fund Grant no. 02-01-04 SF 0199 from the Ministry of Science, Technology and Innovation (MOSTI), Malaysia.

\section{References}

[1] S. Faine, B. Adler, C. A. Bolin, and P. Perolat, Leptospira and Leptospirosis, Medisci Press, Melbourne, Australia, 2nd edition, 1999.

[2] A. R. Bharti, J. E. Nally, J. N. Ricaldi et al., "Leptospirosis: a zoonotic disease of global importance," Lancet Infectious Diseases, vol. 3, no. 12, pp. 757-771, 2003.

[3] A. F. B. Victoriano, L. D. Smythe, N. Gloriani-Barzaga et al., "Leptospirosis in the Asia Pacific region," BMC Infectious Diseases, vol. 9, article 147, 2009.
[4] B. Siti-Khairani, Epidemiology of Leptospira interrogans Serovar Hardjo Infection in Cattle [Ph.D. thesis], University Putra Malaysia, Selangor, Malaysia, 2001.

[5] P. N. Levett, "Leptospirosis," Clinical Microbiology Reviews, vol. 14, no. 2, pp. 296-326, 2001.

[6] T. K. Koay, S. Nirmal, L. Noitie, and E. Tan, "An epidemiological investigation of an outbreak of leptospirosis associated with swimming, Beaufort, Sabah," Medical Journal of Malaysia, vol. 59, no. 4, pp. 455-459, 2004.

[7] A. I. Ko, C. Goarant, and M. Picardeau, "Leptospira: the dawn of the molecular genetics era for an emerging zoonotic pathogen," Nature Reviews Microbiology, vol. 7, no. 10, pp. 736-747, 2009.

[8] D. J. Brenner, A. F. Kaufmann, K. R. Sulzer, A. G. Steigerwalt, F. C. Rogers, and R. S. Weyant, "Further determination of DNA relatedness between serogroups and serovars in the family Leptospiraceae with a proposal for Leptospira alexanderi sp. nov. and four new Leptospira genomospecies," International Journal of Systematic Bacteriology, vol. 49, no. 2, pp. 839-858, 1999.

[9] A. de la Peña-Moctezuma, D. M. Bulach, and B. Adler, "Genetic differences among the LPS biosynthetic loci of serovars of Leptospira interrogans and Leptospira borgpetersenii," FEMS Immunology and Medical Microbiology, vol. 31, no. 1, pp. 73-81, 2001.

[10] P. A. Cullen, D. A. Haake, and B. Adler, "Outer membrane proteins of pathogenic spirochetes," FEMS Microbiology Reviews, vol. 28, no. 3, pp. 291-318, 2004.

[11] P. A. Cullen, X. Xu, J. Matsunaga et al., "Surfaceome of Leptospira spp," Infection and Immunity, vol. 73, no. 8, pp. 48534863, 2005.

[12] P. A. Cullen, D. A. Haake, D. M. Bulach, R. L. Zuerner, and B. Adler, "LipL21 is a novel surface-exposed lipoprotein of pathogenic Leptospira species," Infection and Immunity, vol. 71, no. 5, pp. 2414-2421, 2003.

[13] Z. Wang, L. Jin, and A. Wegrzyn, "Leptospirosis vaccines," Microbial Cell Factories, vol. 6, article 39, 2007.

[14] M. Pinne and D. A. Haake, "A comprehensive approach to identification of surface-exposed, outer membrane-spanning proteins of Leptospira interrogans," PLoS ONE, vol. 4, no. 6, Article ID e6071, 2009.

[15] J. Sambrook and D. W. Russell, Molecular Cloning: A Laboratory Manual, Cold Spring Harbor Laboratory Press, Cold Spring Harbor, NY, USA, 2001.

[16] U. K. Laemmli, "Cleavage of structural proteins during the assembly of the head of bacteriophage T4," Nature, vol. 227, no. 5259, pp. 680-685, 1970.

[17] E. S. Shang, T. A. Summers, and D. A. Haake, "Molecular cloning and sequence analysis of the gene encoding LipL41, a surface-exposed lipoprotein of pathogenic Leptospira species," Infection and Immunity, vol. 64, no. 6, pp. 2322-2330, 1996.

[18] D. A. Haake, E. M. Walker, D. R. Blanco, C. A. Bolin, J. N. Miller, and M. A. Lovett, "Changes in the surface of Leptospira interrogans serovar grippotyphosa during in vitro cultivation," Infection and Immunity, vol. 59, no. 3, pp. 1131-1140, 1991.

[19] R. L. Zuerner, W. Knudtson, C. A. Bolin, and G. Trueba, "Characterization of outer membrane and secreted proteins of Leptospira interrogans serovar pomona," Microbial Pathogenesis, vol. 10, no. 4, pp. 311-322, 1991. 
[20] C. G. O'Connor and L. K. Ashman, "Application of the nitrocellulose transfer technique and alkaline phosphatase conjugated anti-immunoglobulin for determination of the specificity of monoclonal antibodies to protein mixtures," Journal of Immunological Methods, vol. 54, no. 2, pp. 267-271, 1982.

[21] D. D. Hartwig, F. K. Seixas, G. M. Cerqueira, A. J. A. McBride, and O. A. Dellagostin, "Characterization of the immunogenic and antigenic potential of putative lipoproteins from Leptospira interrogans," Current Microbiology, vol. 62, no. 4, pp. 1337-1341, 2011.

[22] W. Viratyosin, S. Ingsriswang, E. Pacharawongsakda, and P. Palittapongarnpim, "Genome-wide subcellular localization of putative outer membrane and extracellular proteins in Leptospira interrogans serovar Lai genome using bioinformatics approaches," BMC Genomics, vol. 9, article 181, 2008.

[23] J. C. Setubal, M. Reis, J. Matsunaga, and D. A. Haake, "Lipoprotein computational prediction in spirochaetal genomes," Microbiology, vol. 152, no. 1, pp. 113-121, 2006.

[24] H. He, W. Wang, Z. Wu, Z. Lv, J. Li, and L. Tan, "Protection of guinea pigs against Leptospira interrogans serovar Lai by lipL21 DNA vaccine," Cellular and Molecular Immunology, vol. 5, no. 5, pp. 385-391, 2008.

[25] P. S. Cheema, S. K. Srivastava, R. Amutha, S. Singh, H. Singh, and M. Sandey, "Detection of pathogenic leptospires in animals by PCR based on lipL21 and lipL32 genes," Indian Journal of Experimental Biology, vol. 45, no. 6, pp. 568-573, 2007.

[26] M. Picardeau, "Conjugative transfer between Escherichia coli and Leptospira spp. as a new genetic tool," Applied and Environmental Microbiology, vol. 74, no. 1, pp. 319-322, 2008.

[27] H.-L. Yang, Y.-Z. Zhu, J.-H. Qin et al., "In silico and microarraybased genomic approaches to identifying potential vaccine candidates against Leptospira interrogans," BMC Genomics, vol. 7, article 293, 2006.

[28] D. A. Haake, G. Chao, R. L. Zuerner et al., “The leptospiral major outer membrane protein LipL32 is a lipoprotein expressed during mammalian infection," Infection and Immunity, vol. 68, no. 4, pp. 2276-2285, 2000.

[29] D. A. Haake, C. I. Champion, C. Martinich et al., "Molecular cloning and sequence analysis of the gene encoding OmpL1, a transmembrane outer membrane protein of pathogenic Leptospira spp," Journal of Bacteriology, vol. 175, no. 13, pp. 42254234, 1993.

[30] J. Matsunaga, K. Werneid, R. L. Zuerner, A. Frank, and D. A. Haake, "LipL46 is a novel surface-exposed lipoprotein expressed during leptospiral dissemination in the mammalian host," Microbiology, vol. 152, no. 12, pp. 3777-3786, 2006.

[31] D. Luo, F. Xue, D. M. Ojcius et al., "Protein typing of major outer membrane lipoproteins from Chinese pathogenic Leptospira spp. and characterization of their immunogenicity," Vaccine, vol. 28, no. 1, pp. 243-255, 2009.

[32] S. Dey, C. M. Mohan, T. M. A. S. Kumar, P. Ramadass, A. M. Nainar, and K. Nachimuthu, "Recombinant LipL32 antigenbased single serum dilution ELISA for detection of canine leptospirosis," Veterinary Microbiology, vol. 103, no. 1-2, pp. 99106, 2004.

[33] K. Natarajaseenivasan, P. Vijayachari, S. Sharma, A. P. Sugunan, J. Selvin, and S. C. Sehgal, "Serodiagnosis of severe leptospirosis: evaluation of ELISA based on the recombinant OmpL1 or LipL41 antigens of Leptospira interrogans serovar autumnalis,"
Annals of Tropical Medicine and Parasitology, vol. 102, no. 8, pp. 699-708, 2008.

[34] R. U. M. Palaniappan, Y.-F. Chang, S. S. D. Jusuf et al., "Cloning and molecular characterization of an immunogenic LigA protein of Leptospira interrogans," Infection and Immunity, vol. 70, no. 11, pp. 5924-5930, 2002.

[35] M. Subathra, T. M. A. Senthilkumar, G. L. Ramya, and P. Ramadass, "Evaluation of a novel IGG-ELISA for serodiagnosis of leptospirosis using recombinant LipL32 antigen of L. Interrogans serovar icterohaemorrhagiae in dogs," Asian Journal of Microbiology, Biotechnology and Environmental Sciences, vol. 10, no. 2, pp. 445-447, 2008.

[36] M. Varma, M. Morgan, B. Jasani, P. Tamboli, and M. B. Amin, "Polyclonal anti-PSA is more sensitive but less specific than monoclonal anti-PSA: implications for diagnostic prostatic pathology," American Journal of Clinical Pathology, vol. 118, no. 2, pp. 202-207, 2002. 


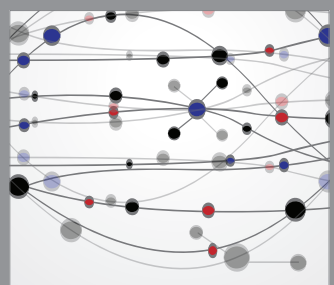

The Scientific World Journal
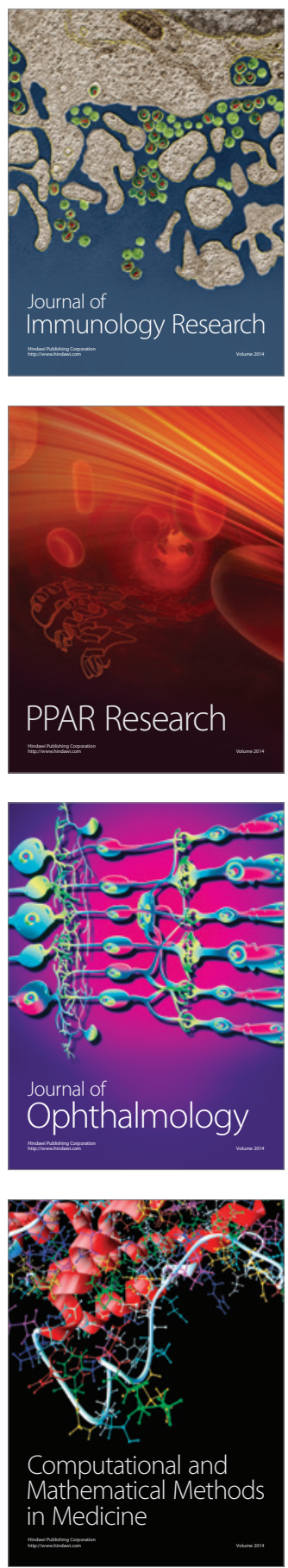

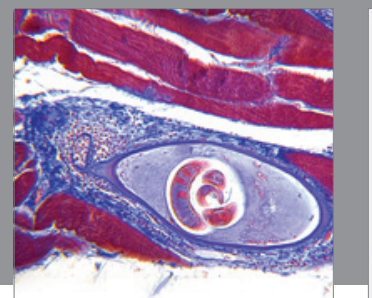

Gastroenterology

Research and Practice
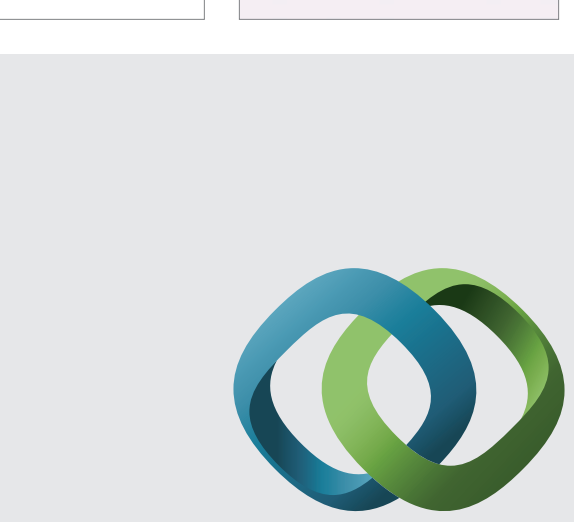

\section{Hindawi}

Submit your manuscripts at

http://www.hindawi.com
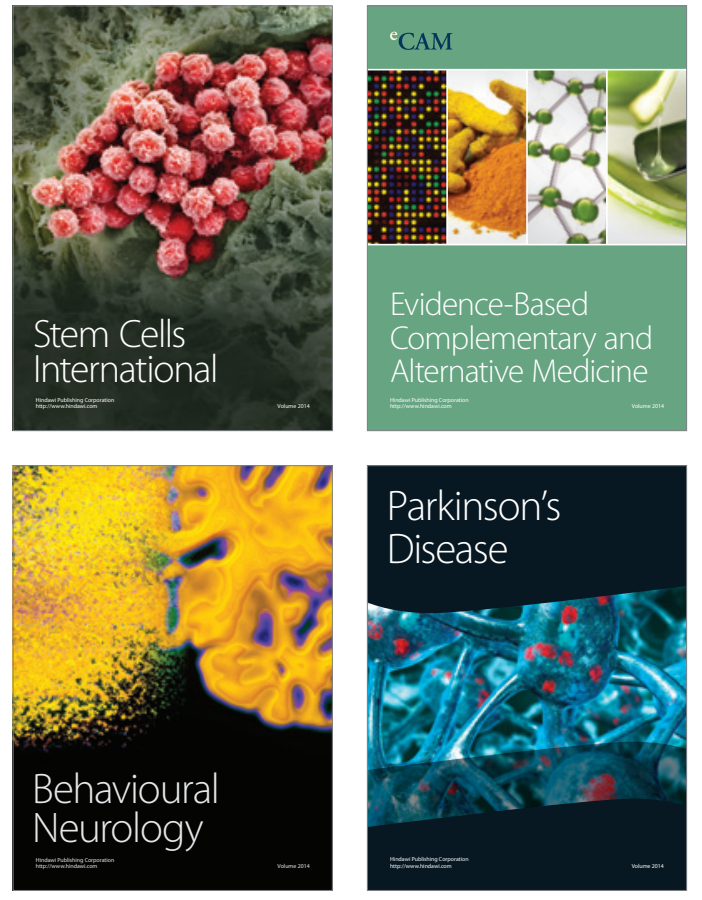
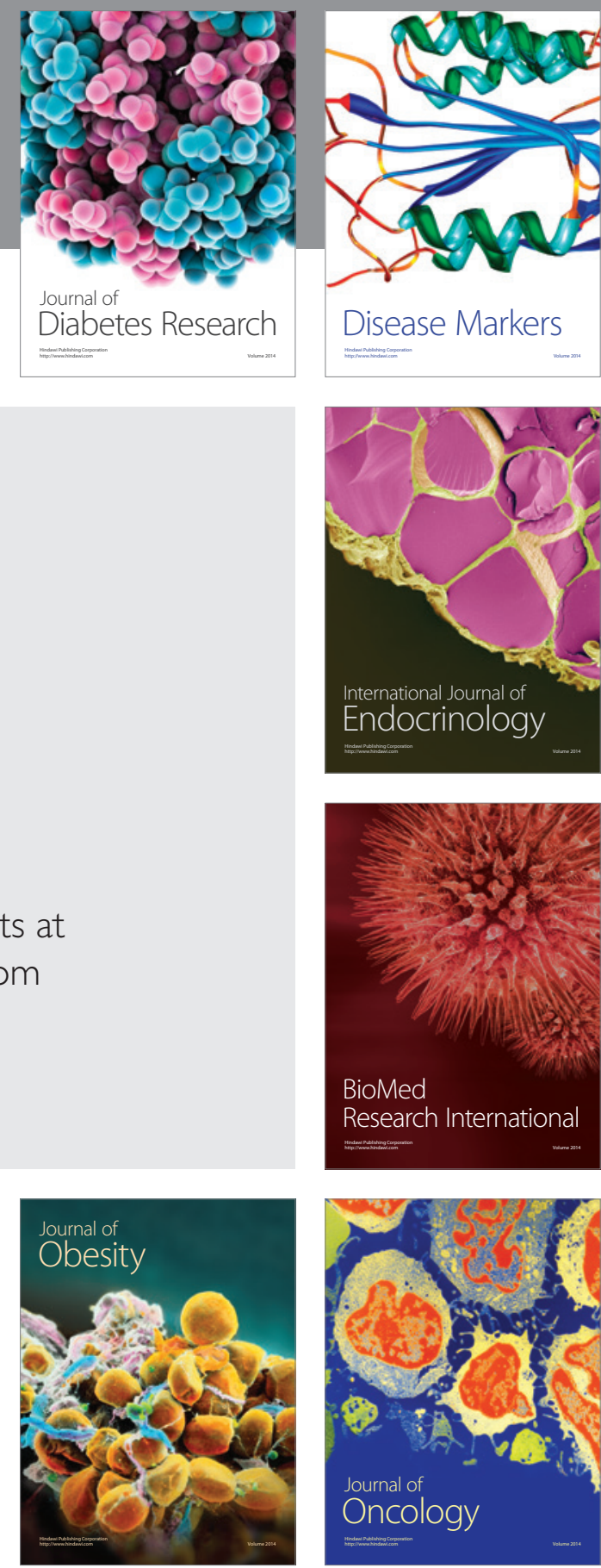

Disease Markers
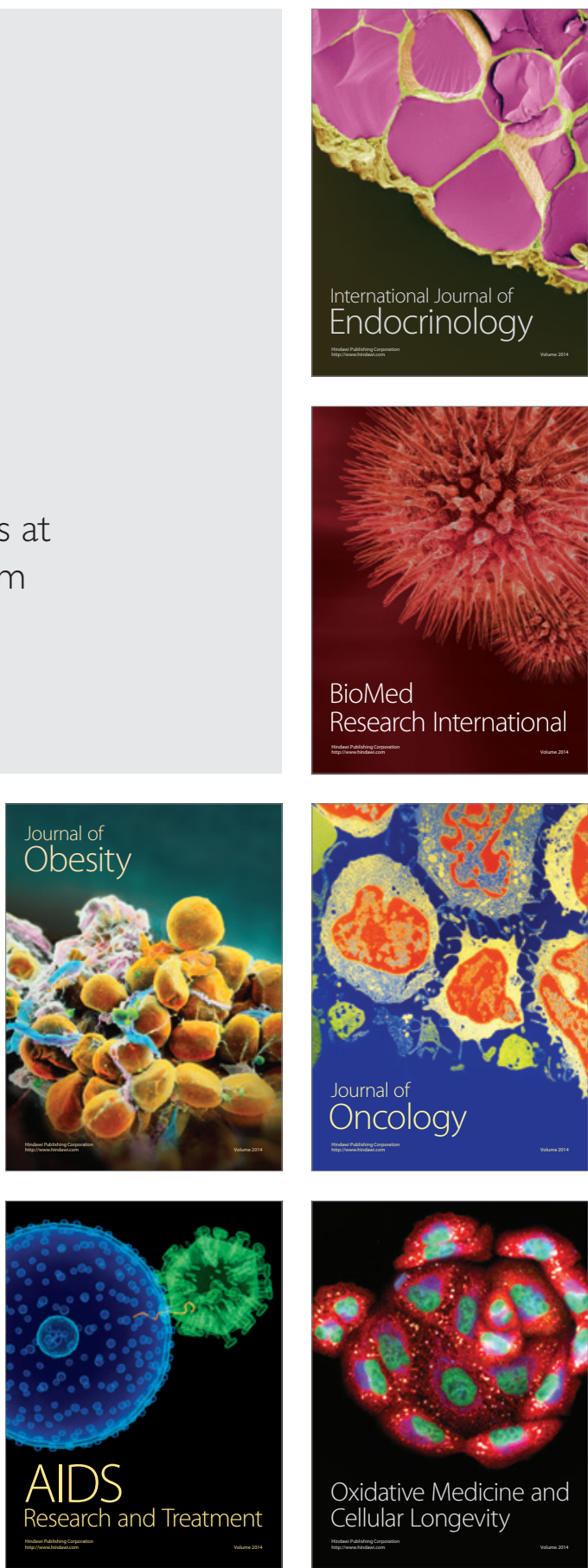